\title{
On the calculation of thermoelastic processes in a cylindrical shell with local heat sources
}

\author{
Maksymuk O. ${ }^{1}$, Ganulich N. ${ }^{2}$ \\ ${ }^{1}$ Ivan Franko National University of Lviv \\ 1 Universytetska str., 79000, Lviv, Ukraine \\ ${ }^{2}$ Pidstryhach Institute for Applied Problems of Mechanics and Mathematics of NAS of Ukraine \\ 3-b Naukova str., 79060, Lviv, Ukraine
}

(Received 8 November 2017)

\begin{abstract}
A quasistatic problem of thermoelasticity for a yielding cylindrical finite-length shell under the action of axially symmetric heat sources in a wide range of heating modes is solved. The numerical calculation of the temperature fields, the ring forces and the bending moments for the values of the time at which they reach the maximal levels is carried out. The influence of the shear degree is studied.
\end{abstract}

Keywords: thermoelasticity, cylindrical shell, heat sources, ring forces, bending moments, shear degree.

2000 MSC: $26 \mathrm{~A} 33,74 \mathrm{~F} 05$

UDC: 539.3

DOI: $10.23939 / \mathrm{mmc} 2017.02 .162$

\section{Introduction}

Along with wide adoption of thin-walled thermoplastic pipes (cylindrical shells) in thermal power systems, a problem of calculation of strains that arise as a result of the nonuniformity of heat distributions both in length and in time often emerges, which may cause the loss of operational capability by not only an individual element of the structure but also by the whole system. The problem of thermal stresses in a cylindrical shell is highlighted by many scientific studies [1-4], but in the study of thermoelastic processes in thermoplastics, it is necessary to take into account the deformative features of their behavior (in particular, their ability to interlayer shears of individual fibers), which is represented in [5-8]. These features are taken into account in the model of S. Tymoshenko [9], according to which the normal to the surface of the shell in the process of deformation turns through some angle, without changing its length. In this formulation, previously we solved $[10,11]$ the axisymmetric problem of thermoelasticity both for infinitely long and short shells under the action of local longitudinal heat sources in the steady regime of heating, and we carried out a comparison of the results with the corresponding values of the calculated values obtained for the problem in the classical formulation [12] without taking into account the interstrains of the layers.

In this paper, we have considered four cases of heating of a volumetrically elastic cylindrical shell of a finite length by local heat sources acing in the time modes actual for practical applications, and have established the quantitative differences of the effect of interstrain at various degrees of the yielding of the material.

\section{The problem formulation}

The quasistatic problem of thermoelasticity for a cylindrical shell with the wall thickness $2 h$ and the radius $R$ for the time-dependent ( $t$ is the time) axisymmetric heat sources $Q(x ; \tau)$, where $x$ is the axial radius-referred coordinate, consists in the consequent solving the heat equation [13] under the condition of Newtonian heat transfer to the environment 


$$
\frac{\partial^{2} T}{\partial x^{2}}-\frac{\partial T}{\partial \tau}-\beta^{2} T(x ; \tau)=-\frac{R^{2}}{\alpha_{t}} Q(x ; \tau)
$$

and the equation of the shell bending with taking into account the interstrain of the fibers

$$
\frac{d^{4} W}{d x^{4}}-2 g^{2} \frac{d^{2} W}{d x^{2}}+4 k^{4} W(x ; \tau)=4 k^{4} R \beta_{t}\left(T(x ; \tau)-\varepsilon \frac{d^{2} T}{d x^{2}}\right),
$$

where $T(x ; \tau)$ is the difference between the temperature at any point of the shell and the constant temperature of the environment referred to the middle surface, $W(x ; \tau)$ are the normal deflections of the shell, $\tau=t /\left(\alpha R^{2}\right), \beta^{2}=\kappa R^{2} /\left(\alpha_{t} h\right), \alpha=C_{v} \rho / \alpha_{t}, C_{v}$ is the specific heat of the material at a constant volume $V, \rho$ is the specific density, $\alpha_{t}$ and $\kappa$ are the coefficients of heat conduction and heat emission respectively, $2 g^{2}=E /\left(k^{\prime} G^{\prime}\right), 4 k^{4}=3\left(1-\nu^{2}\right)(R / h)^{2}, \varepsilon=g^{2} /\left(2 k^{4}\right), E$ is the Young's modulus, $k^{\prime}$ and $G^{\prime}$ are the shear coefficient and the shear modulus, $\nu$ and $\beta_{t}$ are the Poisson's ratio and the coefficients of linear expansion of the shell material.

The distribution of heat sources acting in the ring $x \in[0 ; a]$ of the shell, we give with the function finite in time

$$
Q(x ; \tau)=Q_{0} \theta(x ; a)\left[C^{*} \theta(\tau)+P_{m}(\tau) e^{-\beta_{0}^{2} \tau}\right],(\tau>0),
$$

where $Q_{0}=$ const, $C^{*}=$ const, $\beta_{0}$ are the parameter of sources damping, $P_{m}(\tau)=\sum_{k=0}^{m} C_{k} \tau^{k}$ is a polynomial, $\theta(x ; a)=\theta(x+a)-\theta(x-a), \theta(x)$ is the Heaviside step function.

\section{Construction of the temperature field}

The solution of Eq. (1) for the shell with the length $l$ referred to the radius $R$ and with the initial condition

$$
T(x ; 0)=0
$$

we construct with the help of the Laplace transform, which, under the condition of the temperature being finite in time, for $\tau \rightarrow \infty$ leads to the usual differential equation

$$
\frac{d^{2} \tilde{T}}{d x^{2}}-\left(p+\beta^{2}\right) \tilde{T}(x ; p)=-\frac{R^{2}}{\alpha_{t}} \tilde{Q}(x ; p),
$$

where $\tilde{T}(x ; p)=\int_{0}^{\infty} T(x ; \tau) e^{-p \tau} d \tau, \tilde{Q}(x ; p)=\int_{0}^{\infty} Q(x ; \tau) e^{-p \tau} d \tau$ are the Laplace transforms with the transformation parameter $p$.

It is easy to show that the mapping of the source function (3) has the form:

$$
\tilde{Q}(x ; p)=Q_{0} \theta(x ; a)\left(\frac{C^{*}}{p}+\sum_{k=0}^{m} \frac{C_{k} k !}{\left(p+\beta_{0}^{2}\right)^{k+1}}\right) .
$$

By expansion of the function of the sources (3) in an even manner with the period $2 l$ over the entire axis $0 x$, the solution of Eq. (5) can be given in the Fourier series [14] with coefficients $\tilde{a}_{n}(p)$, $(n=1,2,3, \ldots)$ as functions of the transformation parameter $p$ :

$$
\tilde{T}(x ; p)=\frac{\tilde{a}_{0}(p)}{2}+\sum_{n=1}^{\infty} \tilde{a}_{n}(p) \cos \left(\lambda_{n} x\right), \quad \lambda_{n}=\frac{n \pi}{l} .
$$

The unit step function $\theta(x ; a)$ from Eq. (3) can be also presented in the final form in a similar series:

$$
\theta(x ; a)=\frac{a}{l}+\frac{2}{\pi} \sum_{n=1}^{\infty} \frac{\sin \left(\lambda_{n} a\right)}{n} \cos \left(\lambda_{n} x\right) .
$$


Substituting these series into Eq. (5) and equalizing the coefficients for the same harmonics, we find the expressions of the coefficients $\tilde{a}_{n}(p)$ :

$$
\begin{aligned}
& \tilde{a}_{0}(p)=\frac{2 a q_{0}}{\beta_{t} l\left(p+\beta^{2}\right)}\left(\frac{C^{*}}{p}+\sum_{k=0}^{m} \frac{C_{k} k !}{\left(p+\beta_{0}^{2}\right)^{k+1}}\right), \\
& \tilde{a}_{n}(p)=\frac{2 q_{0}}{\pi \beta_{t}}\left[\frac{C^{*}}{p}+\sum_{k=0}^{m} \frac{C_{k} k !}{\left(p+\beta_{0}^{2}\right)^{k+1}}\right] \frac{\sin \left(\lambda_{n} a\right)}{n\left(p+\omega_{n}^{2}\right)},
\end{aligned}
$$

where $q_{0}=\beta_{t} R^{2} Q_{0} \alpha_{t}^{-1}, \omega_{n}^{2}=\lambda_{n}^{2}+\beta^{2}$.

The expression of the mapping of the temperature field (7) acquires the following form:

$$
\tilde{T}(x ; p)=\frac{q_{0}}{\beta_{t}}\left(\frac{C^{*}}{p}+\sum_{k=0}^{m} \frac{C_{k} k !}{\left(p+\beta_{0}^{2}\right)^{k+1}}\right)\left(\frac{a}{l\left(p+\beta^{2}\right)}+\frac{2}{\pi} \sum_{n=1}^{\infty} \frac{\sin \left(\lambda_{n} a\right)}{n\left(p+\omega_{n}^{2}\right)} \cos \left(\lambda_{n} x\right)\right) .
$$

Decomposing the fractions with denominators $p\left(p+\beta^{2}\right), p\left(p+\omega_{n}^{2}\right),\left(p+\beta^{2}\right)\left(p+\beta_{0}^{2}\right)^{k+1},(p+$ $\left.\omega_{n}^{2}\right)\left(p+\beta_{0}^{2}\right)^{k+1}$ into common fractions and using the table of Laplace inversions and the theorem on the differentiation of the mapping of the function $\tilde{f}(p)$ - the original of $f(\tau)$, namely $(-1)^{n} \frac{d^{n} \tilde{f}(p)}{d p^{n}} \leftrightarrow$ $\tau^{n} f(\tau)$, after simplifications, we obtain the expression of the temperature field:

$$
\begin{aligned}
T(x ; \tau)= & \frac{q_{0}}{\beta_{t}}\left\{C^{*}\left[\frac{a\left(1-e^{-\beta^{2} \tau}\right)}{\beta^{2} l}+\frac{2}{\pi} \sum_{n=1}^{\infty}\left(1-e^{-\omega_{n}^{2} \tau}\right) \frac{\sin \left(\lambda_{n} a\right)}{n} \cos \left(\lambda_{n} x\right)\right]\right. \\
& -\frac{a}{l} \sum_{k=0}^{m} C_{k}\left(\frac{k ! e^{-\beta^{2} \tau}}{\left(\beta_{0}^{2}-\beta^{2}\right)^{k+1}}-\frac{1}{k+1} \sum_{j=0}^{k} \frac{\tau^{j} e^{-\beta_{0}^{2} \tau}}{\left(\beta_{0}^{2}-\beta^{2}\right)^{k-j+1}}\right) \\
& \left.+\frac{2}{\pi} \sum_{n=1}^{\infty} \sum_{k=0}^{m} C_{k}\left[\frac{k ! e^{-\omega_{n}^{2} \tau}}{\left(\beta_{0}^{2}-\omega_{n}^{2}\right)^{k+1}}-\frac{1}{k+1} \sum_{j=0}^{k} \frac{\tau^{j} e^{-\beta_{0}^{2} \tau}}{\left(\beta_{0}^{2}-\omega_{n}^{2}\right)^{k-j+1}}\right] \frac{\sin \left(\lambda_{n} a\right)}{n} \cos \left(\lambda_{n} x\right)\right\} .
\end{aligned}
$$

This formula determines the temperature distribution when the shell is heated by heat sources (3) in a wide range of time regimes, which is ensured by a proper selection of coefficients $C^{*}$ and $C_{k}$.

\section{Temperature field under the action of individual cases of heating the shell}

Let us consider several shell heating modes important for application:

$$
\begin{aligned}
\text { I. } & C^{*}=0, C_{0}=1, C_{k}=0,(k=1,2, \ldots, m): Q(x ; \tau)=Q_{0} \theta(x ; a) e^{-\beta_{0}^{2} \tau} ; \\
I I . & C^{*}=0, C_{0}=0, C_{1}=1, C_{k}=0,(k=2,3,4, \ldots, m): Q(x ; \tau)=Q_{0} \theta(x ; a) \tau e^{-\beta_{0}^{2} \tau} ; \\
I I I . & C^{*}=1, C_{0}=-1, C_{k}=0,(k=1,2, \ldots, m): Q(x ; \tau)=Q_{0} \theta(x ; a)\left(1-e^{-\beta_{0}^{2} \tau}\right) ; \\
I V . & C^{*}=C_{0}=1 ; C_{k}=0,(k=1,2, \ldots, m): Q(x ; \tau)=Q_{0} \theta(x ; a)\left(1+e^{-\beta_{0}^{2} \tau}\right) .
\end{aligned}
$$

It is obvious, the distribution (11) describes the process of heating the shell in a damping mode with the maximal value of the density of the sources $Q=Q_{0}$ at the moment of their activation $\tau=0$; the distribution (12) describes the process of gradual heating of the shell from the zero state of the sources to the level with the maximal density $Q=\left(e \beta_{0}^{2}\right)^{-1} Q_{0}$ at the time moments $\tau=\beta_{0}^{-2}$ with its subsequent monotone descent to zero in the asymptotic mode $(\tau \rightarrow \infty)$; the distribution (13) describes the process of heating the shell with sources of increasing density from zero for $\tau=0$ to $Q=Q_{0}$ at $\tau \rightarrow \infty$; and the distribution (14) is the heating process with asymptotic twice decrease in the density of sources from the maximal value $Q=2 Q_{0}$ at the moment of their activation to $Q=Q_{0}$ at $\tau \rightarrow \infty$. 
The expressions of the temperature corresponding to the sources distributions (11)-(14) are derived from (10) and are expressed by the formula common to all cases:

$$
T(x ; \tau)=\frac{2 q_{0}}{\beta_{t}}\left[\frac{a}{2 l} \psi_{0}^{(j)}(\tau)+\frac{1}{\pi} \sum_{n=1}^{\infty} \psi_{n}^{(j)}(\tau) \frac{\sin \left(\lambda_{n} a\right)}{n} \cos \left(\lambda_{n} x\right)\right], \quad(j=1,2,3,4)
$$

where the time functions are introduced:

$$
\begin{array}{ll}
\psi_{n}^{(1)}(\tau)=\nu_{n}^{-2}\left(e^{-\beta_{0}^{2} \tau}-e^{-\nu_{n}^{2} \tau}\right), & \psi_{n}^{(2)}(\tau)=\nu_{n}^{-4}\left(e^{-\omega_{n}^{2} \tau}+\left(\nu_{n}^{2} \tau-1\right) e^{-\beta_{0}^{2} \tau}\right), \\
\psi_{n}^{(3)}(\tau)=\omega_{n}^{-2}-\nu_{n}^{-2} e^{-\beta_{0}^{2} \tau}+\beta_{0}^{2}\left(\nu_{n}^{2} \omega_{n}^{2}\right)^{-1} e^{-\omega_{n}^{2 \tau}}, & \psi_{n}^{(4)}(\tau)=\omega_{n}^{-2}+\nu_{n}^{-2} e^{-\beta_{0}^{2} \tau}-\left(\nu_{n}^{2} \omega_{n}^{2}\right)^{-1}\left(\nu_{n}^{2}+\omega_{n}^{2}\right) e^{-\omega_{n}^{2} \tau},
\end{array}
$$

$\nu_{n}^{2}=\omega_{n}^{2}-\beta_{0}^{2},(n=0,1,2, \ldots)$, note that the upper index in the expressions $\psi_{n}^{(j)}(\tau)$ means the number of sources (11)-(14).

Since $\psi_{n}^{(j)}(0)=0,(j=1,2,3,4)$, then from the solution (15) it is clear that the initial condition (4) is satisfied in all cases of the action of the sources $Q(x ; \tau)$.

We also note that under the equality of the reduced coefficient of heat conductivity-emission $\beta$ and the parameter of sources damping $\beta_{0}$ after the disclosure of uncertainties from (15) follows the equality:

$$
T(x ; \tau)=\frac{2 q_{0}}{\beta_{t}}\left[\frac{a}{2 \beta^{2} l} \lim _{\beta_{0} \rightarrow \beta} \psi_{0}^{(j)}(\tau)+\frac{1}{\pi} \sum_{n=1}^{\infty} \psi_{n}^{(j)}\left(\tau ; \beta_{0}=\beta\right) \frac{\sin \left(\lambda_{n} a\right)}{n} \cos \left(\lambda_{n} x\right)\right], \quad(j=1,2,3,4),
$$

and for all distributions of sources $\lim _{\beta_{0} \rightarrow \beta} \psi_{0}^{(j)}(\tau)$, there exist simple expressions, which are not represented here.

\section{Construction of functions of deflections, forces, and moments}

The solution of the deflection equation (2) with regard to the parity of the perturbing stress-deformed shell state functions of the sources (3) and of the temperature (15), which automatically ensures the satisfaction of the boundary conditions of the parity, i.e. the conditions for the absence of angles of rotation and of the cross-sections forces at the ends of the shell, namely

$$
W_{x}^{\prime}(0 ; \tau)=W_{x}^{\prime}(l ; \tau)=0, \quad W_{x x x}^{\prime \prime \prime}(0 ; \tau)=W_{x x x}^{\prime \prime \prime}(l ; \tau)=0,
$$

we also represent in a Fourier series with the time-dependent coefficients of expansion:

$$
W(x ; \tau)=\frac{b_{0}(\tau)}{2}+\sum_{n=1}^{\infty} b_{n}(\tau) \cos \left(\lambda_{n} x\right) .
$$

Consistently substituting this series together with the expressions of temperature (15) into Eq. (2) and equalizing the coefficients for the same harmonics $\cos \left(\lambda_{n} x\right)$, we determine the coefficients - the functions $b_{n}(\tau)$ - and, finally, we obtain:

$$
\begin{aligned}
& W(x ; \tau)=2 R q_{0}\left[\frac{a}{2 l} \psi_{0}^{(j)}(\tau)+\frac{4 k^{4}}{\pi} \sum_{n=1}^{\infty} \frac{1+\varepsilon \lambda_{n}^{2}}{\mu_{n}^{4}} \frac{\sin \left(\lambda_{n} a\right)}{n} \psi_{n}^{(j)}(\tau) \cos \left(\lambda_{n} x\right)\right], \quad\left(\beta_{0} \neq \beta\right), \\
& W(x ; \tau)=2 R q_{0}\left[\frac{a}{2 \beta^{2} l} \lim _{\beta_{0} \rightarrow \beta} \psi_{0}^{(j)}(\tau)+\frac{4 k^{4}}{\pi} \sum_{n=1}^{\infty} \frac{1+\varepsilon \lambda_{n}^{2}}{\mu_{n}^{4}} \frac{\sin \left(\lambda_{n} a\right)}{n} \psi_{n}^{(j)}(\tau) \cos \left(\lambda_{n} x\right)\right], \quad\left(\beta_{0}=\beta\right),
\end{aligned}
$$

where we denote $\mu_{n}^{4}=\lambda_{n}^{4}+2 g^{2} \lambda_{n}^{2}+4 k^{4}$. 
For the known deflections $W(x ; \tau)$, we find the ring forces $N(x ; \tau)$ and axial moments $M(x ; \tau)[9,15]$ :

$$
\begin{aligned}
& N(x ; \tau)=2 E h\left(R^{-1} W(x ; \tau)-\beta_{t} T(x ; \tau)\right), \\
& M(x ; \tau)=D R^{-1}\left(2 g^{2}(2 E h)^{-1} N(x ; \tau)-R^{-1} W_{x x}^{\prime \prime}(x ; \tau)\right),
\end{aligned}
$$

here $D=(2 / 3) E h^{3} /\left(1-\nu^{2}\right)$ is the cylindrical rigidity of the shell.

Substituting into these dependences the expressions of temperature (15), the deflection (18) and its derivative of second order $W_{x x}^{\prime \prime}$ with respect to the axial coordinate $x$, we obtain the formulas of forces and moments which are valid for arbitrary ratios between $\beta_{0}$ and $\beta$ :

$$
\begin{aligned}
& N(x ; \tau)=-\frac{4}{\pi} E h q_{0} \sum_{n=1}^{\infty} \frac{\lambda_{n}^{4}}{\mu_{n}^{4}} \frac{\sin \left(\lambda_{n} a\right)}{n} \psi_{n}^{(j)}(\tau) \cos \left(\lambda_{n} x\right), \quad(j=1,2,3,4) ; \\
& M(x ; \tau)=\frac{4}{\pi} E h R q_{0} \sum_{n=1}^{\infty} \frac{\lambda_{n}^{2}}{\mu_{n}^{4}} \frac{\sin \left(\lambda_{n} a\right)}{n} \psi_{n}^{(j)}(\tau) \cos \left(\lambda_{n} x\right), \quad(j=1,2,3,4) .
\end{aligned}
$$

\section{The case of free thermal expansion of a shell for different heating modes}

We note that in the limit case of heating the entire shell $(a=l)$, from $(15)$ the partial cases of free thermal expansion of the shell in time are derived with the constant longitudinal normal displacements $W(\tau)=R \beta_{t} T(\tau)$ caused by the temperature $T(x ; \tau)=\beta_{t}^{-1} q_{0} \psi_{0}^{(j)}(\tau),(j=1,2,3,4)$ which, according to (11)-(14), is determined by the formulas:

$$
\begin{aligned}
& \text { I. } \quad T(\tau)=\frac{q_{0}}{\beta_{t} \beta_{*}^{2}}\left(e^{-\beta_{0}^{2} \tau}-e^{-\beta^{2} \tau}\right), \quad \beta_{0} \neq \beta ; \\
& T(\tau)=\frac{q_{0}}{\beta_{t}} \tau e^{-\beta^{2} \tau}, \quad \beta_{0}=\beta \\
& \text { II. } T(\tau)=\frac{q_{0}}{\beta_{t} \beta_{*}^{4}} e^{-\beta_{0}^{2} \tau}\left(e^{-\beta_{*}^{2} \tau}+\beta_{*}^{2} \tau-1\right), \quad \beta_{0} \neq \beta, \\
& T(\tau)=\frac{q_{0}}{2 \beta_{t}} \tau^{2} e^{-\beta^{2} \tau}, \quad\left(\beta_{0}=\beta\right) ; \\
& \text { III. } T(\tau)=\frac{q_{0}}{\beta_{t} \beta^{2}}\left(1-\frac{\beta^{2} e^{-\beta_{0}^{2} \tau}-\beta_{0}^{2} e^{-\beta^{2} \tau}}{\beta_{*}^{2}}\right), \quad \beta_{0} \neq \beta, \\
& T(\tau)=\frac{q_{0}}{\beta_{t} \beta^{2}}\left(1-\left(1+\beta^{2} \tau\right) e^{-\beta^{2} \tau}\right), \quad \beta_{0}=\beta ; \\
& I V . \quad T(\tau)=\frac{q_{0}}{\beta_{t}}\left(\frac{1}{\beta^{2}}+\frac{1}{\beta_{*}^{2}} e^{-\beta_{0}^{2} \tau}-\frac{\beta^{2}+\beta_{*}^{2}}{\beta^{2} \beta_{*}^{2}} e^{-\beta^{2} \tau}\right), \quad \beta_{0} \neq \beta, \\
& T(\tau)=\frac{q_{0}}{\beta_{t} \beta^{2}}\left(1-\left(1-\beta^{2} \tau\right) e^{-\beta^{2} \tau}\right), \quad \beta_{0}=\beta,
\end{aligned}
$$

where $\beta_{*}^{2}=\beta^{2}-\beta_{0}^{2}$.

Since at the heating of the entire shell $\sin \left(\lambda_{n} a\right)=\sin (n \pi)=0$, then, as it can be seen from Eqs. (22) and (23), for all sources distributions (11)-(14), the forces and axial moments in the shell are completely absent.

It is also easy to show that in this case, the maximal temperature levels, and, hence, the displacements (shell expansion), are reached at the certain moments of time $\tau=\tau_{k}(k=1,2,3,4)$ and are determined by the equalities:

$$
\begin{aligned}
\text { I. } \quad \max T(\tau) & =T\left(\tau_{1}\right)=\frac{q_{0}}{\beta_{t} \beta_{0}^{2}}\left(\frac{\beta_{0}}{\beta}\right)^{2 \frac{\beta^{2}}{\beta_{*}^{2}}}, \quad \tau_{1}=2 \frac{\ln \left(\beta / \beta_{0}\right)}{\beta_{*}^{2}}, \quad\left(\beta_{0} \neq \beta\right) ; \\
\max T(\tau) & =\frac{q_{0}}{\beta_{t} \beta^{2}}, \quad \tau_{1}=\beta^{-2}, \quad\left(\beta_{0}=\beta\right) ;
\end{aligned}
$$




$$
\text { II. } \max T(\tau)=T\left(\tau_{2}\right)=\frac{q_{0}}{\beta_{t} \beta^{2}} \tau_{2} e^{-\beta_{0}^{2} \tau_{2}}, \quad\left(\beta_{0} \neq \beta\right),
$$

where $\tau=\tau_{2}$ is the only non-zero root of the transcendental equation

$$
\begin{gathered}
e^{-\beta_{*}^{2} \tau}+\left(\beta_{0} / \beta\right)^{2} \beta_{*}^{2} \tau-1=0, \\
\max T(\tau)=\frac{2 q_{0}}{\beta^{4} \beta_{t} e^{2}}, \quad \tau_{2}=\frac{2}{\beta^{2}}, \quad\left(\beta_{0}=\beta\right) ;
\end{gathered}
$$

III. Under the action of sources (13), when the entire shell $(a=l)$ is heated, the temperature function has no critical values of time. It is obvious that in this case, the temperature increases over the entire time interval $\tau \in(0 ; \infty)$ from 0 to $q_{0}\left(\beta_{t} \beta^{2}\right)^{-1}$, and for any width of the heating ring $a \leqslant l$ it reaches its maximal level in the asymptotic heating regime at $\tau \rightarrow \infty$ :

$$
\max T(x ; \tau)=T(x ; \infty)=\frac{q_{0}}{\beta_{t}}\left(\frac{a}{\beta^{2} l}+\frac{2}{\pi} \sum_{n=1}^{\infty} \frac{1}{\omega_{n}^{2}} \frac{\sin \left(\lambda_{n} a\right)}{n} \cos \left(\lambda_{n} x\right)\right),
$$

which coincides with the results [11], where the density of heat sources is given by the unit step function $\theta(\tau)$ so that at the infinity the sources for both distributions act with constant intensity $Q=Q_{0}$.

$I V$. In this case, at $a=l$ the maximal temperatures of the shell and the critical values of the time parameter are given by the formulas:

$$
\begin{gathered}
\max T(\tau)=T\left(\tau_{4}\right)=\frac{q_{0}}{\beta_{t} \beta^{2}}\left[1+\left(\frac{\beta_{0}^{2}}{\beta^{2}+\beta_{*}^{2}}\right)^{\frac{\beta_{0}^{2}}{\beta_{*}^{2}}}\right], \quad \tau_{4}=\frac{1}{\beta_{*}^{2}} \ln \left(\frac{\beta^{2}+\beta_{*}^{2}}{\beta_{0}^{2}}\right), \quad\left(\beta_{0} \neq \beta\right), \\
\max T(\tau)=\frac{q_{0}}{\beta_{t} \beta^{2}}\left(1+e^{-2}\right), \quad \tau_{4}=\frac{2}{\beta^{2}}, \quad\left(\beta_{0}=\beta\right) .
\end{gathered}
$$

For all sources distributions $Q(x ; \tau)$, the critical values of $\tau$ and the corresponding maximal values of the temperature $T(x ; \tau)=\left(q_{0}^{*} / \beta_{t}\right) T^{*}(x ; \tau)$ for the uniform heating of the entire shell, where here and thereafter, the product of the reduced density of sources and the widths of the heating ring are constant, i.e. $q_{0}^{*}=a q_{0}=$ const, for the shell length $l=2$ (two radii) and $\beta^{2}=2.32$;

Table 1.

\begin{tabular}{|c|c|c|c|c|c|}
\hline$Q(x ; \tau)$ & $I$ & $I I$ & $I I I$ & $I V$ & $\beta_{0} / \beta$ \\
\hline$\tau$ & 0.464 & 0.95 & $\infty$ & 0.868 & \\
\hline \multirow{2}{*}{$10 T^{*}(x ; \tau)$} & 0.852 & 0.306 & 2.155 & 2.536 & 0.86 \\
\cline { 2 - 6 } & 0.791 & 0.251 & 2.155 & 2.447 & 1 \\
\hline$N(x ; \tau)$ & 0 & 0 & 0 & 0 & - \\
\hline$M(x ; \tau)$ & 0 & 0 & 0 & 0 & - \\
\hline
\end{tabular}
$\beta_{0}^{2}=2$, are represented in Table $1(a=l)$.

\section{The case of placement of sources along the directing line of a shell}

If, on the contrary, we shrink the width of the heating ring $a$ to zero, while maintaining the total density of the sources to be constant in the infinitely narrowing domain $[0 ; a]$ of heating, then from Eqs. (15), (18) and (22), and (23) after disclosure of the uncertainty of the type of the first important limit, the formulas follow that determine the highest levels of the calculated values for a certain time of each distribution (in comparison with the calculated values for any ring widths of the heating $a \in(0 ; l])$ :

$$
\begin{aligned}
T(x ; \tau) & =\frac{2 q_{0}^{*}}{\beta_{t} l}\left[\frac{1}{2} \psi_{0}^{(j)}(\tau)+\sum_{n=1}^{\infty} \psi_{n}^{(j)}(\tau) \cos \left(\lambda_{n} x\right)\right], \\
W(x ; \tau) & =\frac{2 R q_{0}^{*}}{l}\left[\frac{1}{2} \psi_{0}^{(j)}(\tau)+4 k^{4} \sum_{n=1}^{\infty} \frac{1+\varepsilon \lambda_{n}^{2}}{\mu_{n}^{4}} \psi_{n}^{(j)}(\tau) \cos \left(\lambda_{n} x\right)\right],
\end{aligned}
$$

Mathematical Modeling and Computing, Vol. 4, No. 2, pp. 162-170 (2017) 


$$
\begin{aligned}
& N(x ; \tau)=-4 E h l^{-1} q_{0}^{*} \sum_{n=1}^{\infty} \lambda_{n}^{4} \mu_{n}^{-4} \psi_{n}^{(j)}(\tau) \cos \left(\lambda_{n} x\right), \\
& M(x ; \tau)=4 E h l^{-1} R q_{0}^{*} \sum_{n=1}^{\infty} \lambda_{n}^{2} \mu_{n}^{-4} \psi_{n}^{(j)}(\tau) \cos \left(\lambda_{n} x\right), \quad(j=1,2,3,4) .
\end{aligned}
$$

For the distributions $I-I V$, the critical values of time $\tau$ and the temperature values $T(0 ; \tau)=$ $q_{0}^{*} \beta_{t}^{-1} T^{*}(0 ; \tau)$ at which the ring forces $N(0 ; \tau)=-2 E h q_{0}^{*} N^{*}(0 ; \tau)$ and bending moments $M(0 ; \tau)=$ $2 E h R q_{0}^{*} M^{*}(0 ; \tau)$ at the left end of the shell, where the sources of infinitely great densities are concentrated, acquire the maximal values shown in Table $2(a \rightarrow 0)$.

Table 2.

\begin{tabular}{|c|c|c|c|c|c|c|}
\hline$Q(x ; \tau)$ & $I$ & $I I$ & $I I I$ & $I V$ & $E / G^{\prime}$ & $\beta_{0} / \beta$ \\
\hline$\tau$ & 0.065 & 0.545 & $\infty$ & 0.090 & - & - \\
\hline \multirow{2}{*}{$10 T^{*}(0 ; \tau)$} & 2.334 & 0.947 & 6.397 & 5.602 & - & 0.86 \\
\cline { 2 - 7 } & 2.304 & 0.824 & 6.397 & 5.146 & - & 1 \\
\hline \multirow{3}{*}{$10 N^{*}(0 ; \tau)$} & 0.806 & 0.178 & 0.972 & 1.721 & 0 & 0.86 \\
\cline { 2 - 7 } & 0.581 & 0.129 & 0.699 & 1.238 & 40 & 0.86 \\
\cline { 2 - 7 } & 0.516 & 0.113 & 0.620 & 1.098 & 60 & 0.86 \\
\hline \multirow{3}{*}{$10^{2} M^{*}(0 ; \tau)$} & 0.162 & 0.045 & 0.256 & 0.368 & 0 & 0.86 \\
\cline { 2 - 7 } & 0.108 & 0.032 & 0.180 & 0.248 & 40 & 0.86 \\
\cline { 2 - 7 } & 0.094 & 0.028 & 0.159 & 0.216 & 60 & 0.86 \\
\hline
\end{tabular}

\section{Conclusions}

It is easy to show that in the general case for arbitrary values of $0<a<0.5 l$, the maximal levels of the calculated values for all considered distributions of heat sources are also reached at the beginning of the reference $x=0$ and are determined by the corresponding sums (15), (16), (18), (19) and (22), and (23). With the subsequent expansion of the heating ring of the shell, the maxima of forces and moments are steadily shifted to the right along the shell base with the simultaneous decrease of their levels to zero in the limit case of free thermal expansion $(a=l)$.

With this, the critical values of the time parameter $\tau=\tau_{j}^{*},(j=1,2,3,4)$, to which correspond the highest temperatures, can be found approximately, putting in the corresponding expressions $x=0$. Thus, at the above values $\beta_{0}$ and $\beta$ for the heating ring width $a=0.2$, the critical value of the time parameter $\tau_{1}^{*} \approx 0,275$ is for the sources $(11), \tau_{2}^{*} \approx 0.750$ is for the distribution (12), $\tau_{3}^{*} \rightarrow \infty$ is for $(13)$, and $\tau_{4}^{*} \approx 0.525$ is for the distribution (14). In the case $\beta_{0}=\beta$, the critical values $\tau$ are insignificantly different from the indicated above and no qualitative differences contribute to the calculated values, but note that with the approach of the parameter of sources damping $\beta_{0}$ to the reduced coefficient of heat conductivity-emission $\beta$, the level of forces and moments is slightly reduced.

It should be noted that calculated in the same way the maximal levels of ring forces for the source distributions $I, I I$ and $I V$ in the general case of an arbitrary width of the heating ring of the shell are reached somewhat sooner than the values $\tau_{j}^{*}$ mentioned above which correspond to the maxima $T(0 ; \tau)$, which is explained by considerably higher temperature gradients in the initial stages of the heating of the shell in comparison with subsequent stages of its heating. Thus, for the distribution (11), the greatest value of the force (compression) $N(0 ; \tau)$ is reached at $\tau_{0} \approx 0.09$ and $30 \%$ higher than it is at the time $\tau_{0}=0.275$ when the temperature $T(0 ; \tau)$ reaches the maximum. For the distribution of sources (12), the greatest force (compression) corresponds to the moment of time $\tau_{0}=0.545$ and only $7 \%$ exceeds the level of force calculated at $\tau_{0}=0,750$, i.e. the time during which the temperature rises to its maximum, which is explained by a much smoother temperature change in time for this time 
mode. For the distribution (14), the maximum of force is reached for $x=0$ at $\tau_{0} \approx 0.138$ and it is $22 \%$ higher than the force that is reached at $\tau_{0}=0,525$ when the temperature in the shell increases to a maximum. These peculiarities to the same degree the bending moments $M(0 ; \tau)$ feature, and as numerical calculations show, concern all cross-sections and all considered shell heating modes.

These comparisons are made for the classical case of deformation of the shell $\left(E / G^{\prime}=0\right)$, since, as the numerical analysis shows, even though the taking into account the finite rigidity for the shear of the fibers $\left(E / G^{\prime}=40\right.$ and $\left.E / G^{\prime}=60\right)$ to a large extent affects the values of the forces and moments, it contributes no significant differences to their relations in comparison with the classical case. The quantitative differences, as a consequence of the enrichment of the classical model of shell deformation by the shear factor, for those moments of time in which the forces and moments at the left end of the shell reach maximum, can be seen in Table 3 .

Table 3.

\begin{tabular}{|c|c|c|c|c|c|}
\hline$Q(x ; \tau)$ & $I$ & $I I$ & $I I I$ & $I V$ & $E / G^{\prime}$ \\
\hline$\tau$ & 0.090 & 0.545 & $\infty$ & 0.138 & - \\
\hline \multirow{3}{*}{$10 N^{*}(0 ; \tau)$} & 0.349 & 0.079 & 0.435 & 0.746 & 0 \\
\cline { 2 - 6 } & 0.219 & 0.050 & 0.266 & 0.466 & 40 \\
\cline { 2 - 6 } & 0.185 & 0.042 & 0.232 & 0.392 & 60 \\
\hline \multirow{3}{*}{$10^{2} M^{*}(0 ; \tau)$} & 0.133 & 0.047 & 0.207 & 0.308 & 0 \\
\cline { 2 - 6 } & 0.089 & 0.025 & 0.146 & 0.210 & 40 \\
\cline { 2 - 6 } & 0.077 & 0.022 & 0.129 & 0.182 & 60 \\
\hline
\end{tabular}

The change of the calculated values along the shell base for the width of the heating ring $a=0.2$ for the sources $I-I V$ at the time moments corresponding to the maximal levels of ring forces in the case of $E / G^{\prime}=0$ is represented in the graphics of the temperature (Fig. 1), the ring forces (Fig. 2), and the axial moments (Fig. 3).

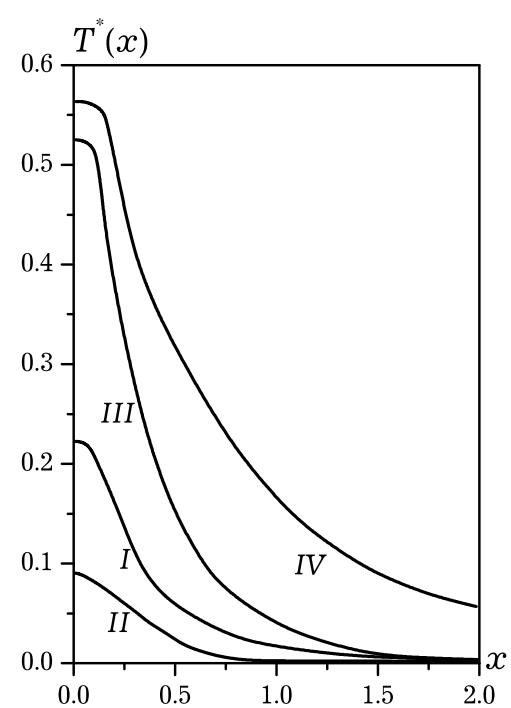

Fig. 1.

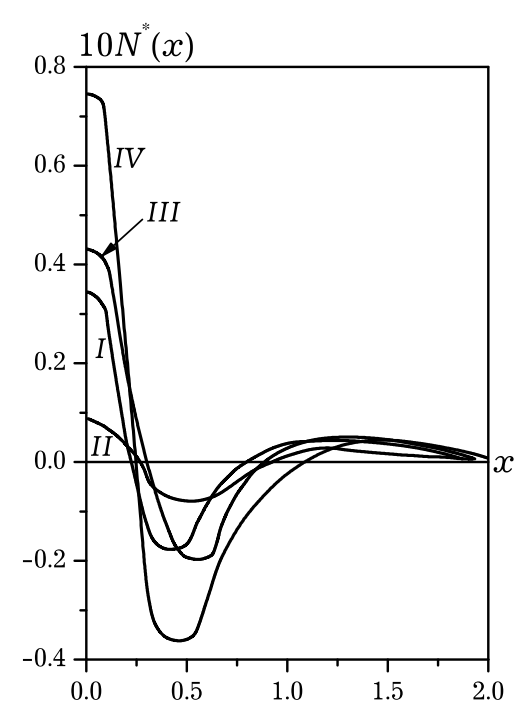

Fig. 2.

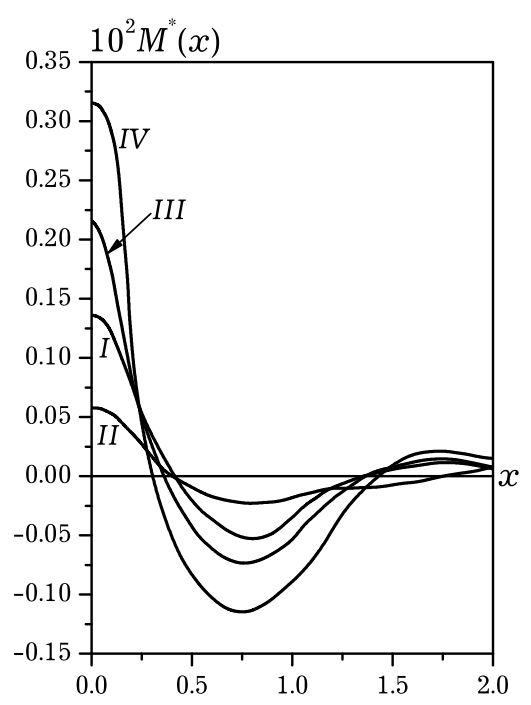

Fig. 3.

These Figs. show that in the distance of two radii from the beginning of the reference the magnitudes of these values practically disappear. At the same time, we note that with an increase in the ratio of $E / G^{\prime}$, these values steadily decrease with the simultaneous damping of the convergence along the axis $0 x$. 
[1] Besedina L., Burak Ya., Podstrigach Ya. On Optimal Heating of Inhomogeneous Shells of Rotation. Izv. Akad. Nauk of SSSR, MTT. 6, 110-116 (1973), (in Russian).

[2] Grigolyuk E., Burak Ya., Podstrigach Ya. On an extremal problem of thermoelasticity for an infinite cylindrical shell. Dokl. AN of SSSR. 174 (3), 534-537 (1967), (in Russian).

[3] Kushnir R., Popovych V. Thermal elasticity of thermosensitive bodies. Lviv, Spolom (2009), (in Ukrainian).

[4] Podstrigach Ya., Shvets R. Thermoelasticity of thin shells. Kiev, Naukova Dumka (1978), (in Russian).

[5] Kopiey B., Maksymuk O., et al. Pumps rod and pipes made of polymeric composites. Lviv, Polygraphy (2003), (in Ukrainian).

[6] Maksimuk A., Shcherbina N., Ganulich N. Designing, calculation, and optimization of polymeric honeycomb pipes. Mechanics of Composite Materials. 44 (6), 601-606 (2008).

[7] Malmeister A., Tamuzh V., Teters G. Resistance of stiff polymeric materials. Riga, Zinatne (1972), (in Russian).

[8] Teters G. Multicriteria optimization of a compozite cylindrical shell subjected to thermal and dynamic actions. Mechanics of Composite Materials. 40 (6), 489-494 (2004).

[9] Pelekh B. The theory of shells with finite shear stiffness. Kiev, Naukova Dumka (1973), (in Russian).

[10] Maksymuk O., Ganulich N. Thermoelasticity of a cylindrical shell with low shear rigidity in a local temperature field. Mat. Methods and Physical Mech. Fields. 58 (3), 26-34 (2015), (in Ukrainian).

[11] Ganulich N. Cylindrical shell of finite length with low shear rigidity under the action of local heat sources. Math. Methods and Physical Mech. Fields. 59 (4), 82-90 (2016), (in Ukrainian).

[12] Ganulich V., Maksymuk O., Ganulich N. Quasistatic thermoelasticity problem for a cylindrical shell with heat sources and heat transfer. Mat. Methods and Physical Mech. Fields. 58 (1), 154-161 (2015), (in Ukrainian).

[13] Bolotin V. Equations of non-stationary temperature fields in thin shells in the presence of heat sources. Appl. Math. \& Mech. 24 (2), 361-336 (1960), (in Russian).

[14] Belyaev N., Ryadno A. Mathematical methods of heat conduction. Kiev, Vishcha school (1993), (in Russian).

[15] Pelekh B., Sukhorolsky M. Contact problems of the theory of elastic anisotropic shells. Kiev, Naukova Dumka' (1980), (in Russian).

\title{
До розрахунку термопружних процесів у циліндричній оболонці з локальними джерелами тепла
}

\author{
Максимук O. ${ }^{1}$, Гануліч Н. ${ }^{2}$ \\ ${ }^{1}$ Львівський начіональний університет імені Івана Франка \\ вул. Університетсъка, 1, 79000, Лъвів, Україна \\ ${ }^{2}$ Інститут прикладних проблем механіки і математики ім. Я. С. Підстригача НАН України \\ вул. Наукова, з-б, 79060, Лъвів, Украӥна
}

\begin{abstract}
Розв'язано квазістатичну задачу термопружності для піддатливої на зсув циліндричної оболонки скінченної довжини за дії осесиметричних джерел тепла у широкому діапазоні режимів нагрівання. Здійснено числовий розрахунок температурних полів, кільцевих зусиль і згинних моментів за тих значень часу, за яких вони досягають максимальних рівнів. Досліджено вплив ступеня зсуву.
\end{abstract}

Ключові слова: термопружність, ииліндрична оболонка, джерела тепла, кільцеві зусилля, заинні моменти, ступінъ зсуву.

2000 MSC: 26A33, 74F05

УдК: 539.3 